\title{
Rapid assessment of road safety policy change: relaxation of the national speed enforcement law in Russia leads to large increases in the prevalence of speeding
}

\author{
Kavi Bhalla, ${ }^{1}$ Nino Paichadze, ${ }^{1}$ Shivam Gupta, ${ }^{1}$ Vladimir Kliavin, ${ }^{2}$ Elena Gritsenko, ${ }^{3}$ \\ David Bishai, ${ }^{1}$ Adnan A Hyder ${ }^{1}$
}

'Johns Hopkins International Injury Research Unit, Johns Hopkins Bloomberg School of Public Health, Baltimore, Maryland, USA

${ }^{2}$ Lipetsk State University of Technology, Lipetsk, Russia ${ }^{3}$ Ivanovo State University of Technology, Ivanovo, Russia

\section{Correspondence to} Dr Kavi Bhalla, Johns Hopkins International Injury Research Unit, Johns Hopkins Bloomberg School of Public Health, $615 \mathrm{~N}$ Wolfe Street E8138, Baltimore, MD, USA; kbhalla@jhsph.edu

Received 3 February 2014

Revised 28 May 2014

Accepted 1 July 2014

Published Online First

22 July 2014

CrossMark

To cite: Bhalla $K$ Paichadze N, Gupta S, et al. Inj Prev 2015:21:53-56.

\section{ABSTRACT}

Reducing vehicle speed is among the most effective road safety strategies. We assess how a new policy in Russia that eliminates fines for driving up to $20 \mathrm{~km} / \mathrm{h}$ above the speed limit has affected the prevalence of speeding. We measured speeds periodically in 13 districts of two Russian regions during 2011-2013 and analysed the effect of the policy using difference-in-differences to control for seasonality. We find that the prevalence of speeding was declining steadily but half of the gains since mid-2011 were lost immediately after the new policy. Overall speeding increased significantly by 13 percentage points ( $p p, 95 \% \mathrm{Cl} 4$ to 19). Speeding more than $10 \mathrm{~km} / \mathrm{h}$ above the limit increased significantly by $10 \mathrm{pp}(95 \% \mathrm{Cl} 2$ to 12), and extreme speeding increased but not significantly $(1.7 \mathrm{pp}, 95 \% \mathrm{Cl}-1.1$ to 4.5). Road traffic injuries will likely increase in Russia unless speeding fines are reinstated.

\section{INTRODUCTION}

Speed management, particularly better enforcement of speed limits, is among the most effective strategies for improving safety. ${ }^{1}$ In recent years, automated technologies for speed measurement have allowed substantial advances in speed enforcement. A Cochrane systematic review concluded that speed cameras reduce the percentage of vehicles speeding by $14-65 \%$, crashes by $8-49 \%$ and deaths and serious injuries by $11-44 \% .^{2}$ Similarly, another systematic review found that all but one of 14 studies reviewed showed that speed cameras were effective at reducing collisions, injuries and deaths. ${ }^{3}$ In France, recent evaluations attributed a 21\% decrease in national fatalities to the populationwide automated speed enforcement programme established in $2003 .^{4}$ Despite the growing number of studies supporting automated speed enforcement, their use remains contentious. Disagreements remain about the extent to which observed reductions in crashes can be attributed to the automated systems as opposed to other effects, such as regression to the mean, and unrelated changes in the traffic environment. ${ }^{5}$

The Russian Federation has increasingly relied on speed cameras for enforcing speed limits. ${ }^{6}$ However, on 1 September 2013, the Russian Federation relaxed national speed enforcement rules by eliminating fines for exceeding the speed limit by up to and including $20 \mathrm{~km} / \mathrm{h}(12 \mathrm{~m} / \mathrm{h}){ }^{7}$ Prior to this date, the enforcement threshold was $10 \mathrm{~km} / \mathrm{h}$ with a fine of 100 Rubles (approximately US\$3) for exceeding the speed limit by $10-20 \mathrm{~km} / \mathrm{h}, 300$ Rubles for 20 $40 \mathrm{~km} / \mathrm{h}$ and higher penalties for higher speeds and repeated speed violations. While the new law eliminated fines for driving up to $20 \mathrm{~km} / \mathrm{h}$ above the limit, the law substantially increased fines for speeding more than $20 \mathrm{~km} / \mathrm{h}$ and more serious violations. In particular, driving $20-40 \mathrm{~km} / \mathrm{h}$ above the limit now results in a fine of 500 Rubles. As a result, the new policy has received substantial attention in the media as a tightening of national road safety regulations. ${ }^{6}$

Given the overwhelming evidence linking speed enforcement to vehicle speeds, we hypothesised that the elimination of fines in Russia would lead to an increase in the proportion of vehicles speeding. We tested this hypothesis by comparing speeds before and after the new policy in two regions in Russia where we had an ongoing road safety project.

\section{METHODS}

We have periodically measured speeds in two regions ('oblasts') of Russia as part of the monitoring and evaluation of the ongoing activities of the Global Road Safety Program, which includes interventions to reduce vehicle speeds. ${ }^{8}$ These include social marketing campaigns encouraging drivers to drive slower. For instance, a campaign titled 'Life is more valuable than speed' was ongoing since 2011 in both oblasts. The social marketing activities were coupled with enhanced enforcement campaigns led by traffic police. Details of our speed measurement protocols are described elsewhere. ${ }^{9}$ Briefly, we have conducted 20 rounds of speed measurements in Lipetskaya (11 rounds; 354409 vehicles) and Ivanovskaya (9 rounds; 297658 vehicles) oblasts since July 2011. The two most recent rounds of measurements in each oblast were conducted after 1 September 2013, when the new enforcement policy went into effect. Other than this relaxation of the speed enforcement law, no other notable change in speed control occurred in September 2013. In each round, speeds are measured in 90 min time blocks on a rural road, city road and highway in each of the 13 districts (6 in Lipetskaya, 7 in Ivanovskaya) distributed across the oblasts. Measurements are conducted in spring, summer and autumn but not in winter. Thus, the measurements incorporate diversity in geographic location, season and road type. Measurement sites were 
chosen to ensure that vehicle speed is not hindered by other environmental factors and only free flow speeds are recorded. Speeds are measured using a radar gun installed inside an unmarked car parked on the side of the street.

Our measurements suggest that speeds may be higher during autumn months (September, October, November) making it important to control for seasonality. Therefore, we evaluated the effect of the policy using difference-in-differences (DiD) ${ }^{10}$ to compare the change in speeding in autumn months relative to change in speeding in non-autumn months. We answer the question, "Was the autumn of 2013 special?" by constructing two population groups that are observed at two time periods. We divide the observed population into vehicles observed during autumn months and vehicles observed during nonautumn months. Similarly, we consider two time periods, year 2013, and other years. Note that the first group (autumn) is exposed to the new policy during the first period (2013) but not during the second period. Written as a regression equation,

$$
\begin{aligned}
\mathrm{V}= & \beta_{0}+\beta_{1} * \text { YR2013 }+\beta_{2} * \text { Autumn }+\beta_{3} * \text { YR2013* Autumn } \\
& +\beta_{4} * \text { month }+\varepsilon
\end{aligned}
$$

where $\mathrm{V}$ is the percentage of vehicles speeding, YR2013 is a dummy variable that is 1 for measurements in 2013 and 0 otherwise, Autumn is a dummy variable that is 1 for
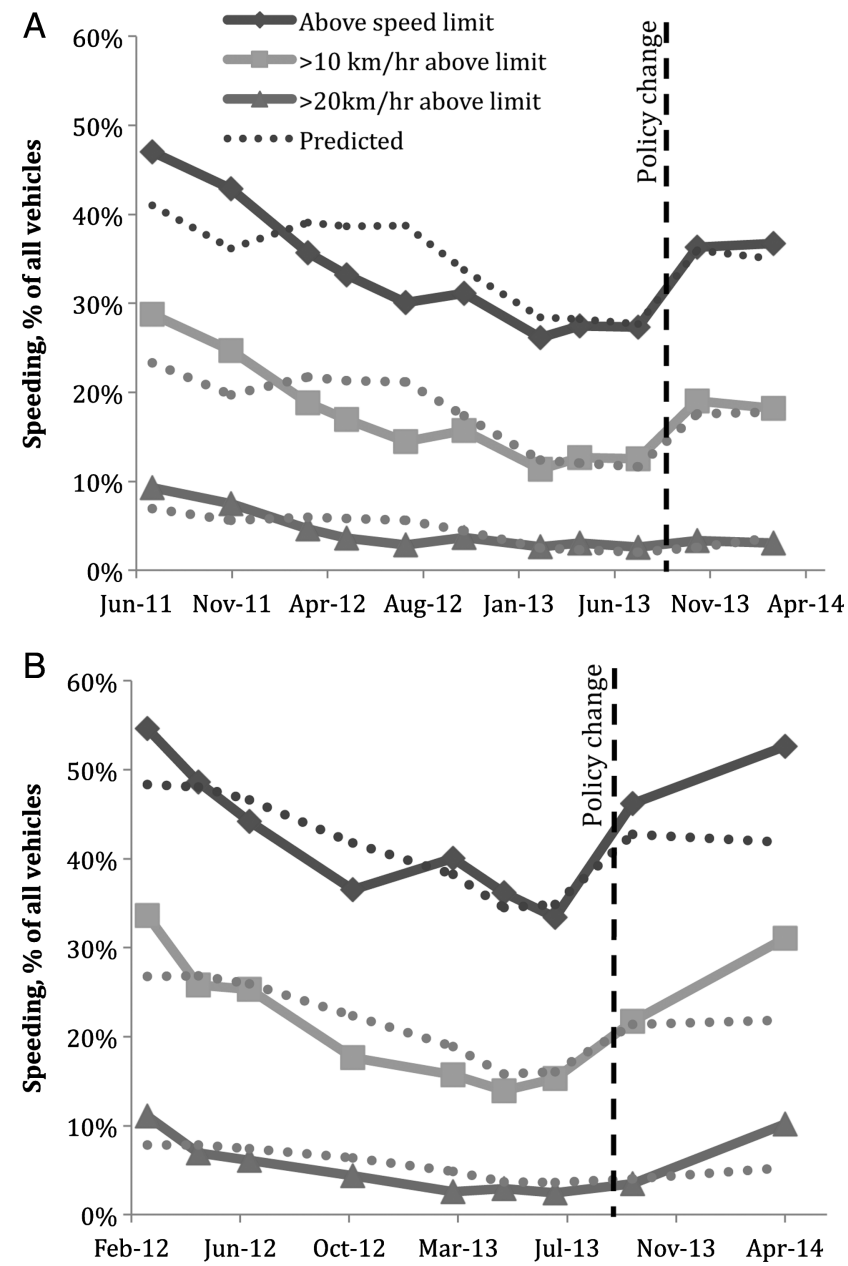

Figure 1 Percentage of vehicles speeding in Lipetskaya $(A)$ and Ivanovskaya (B) oblasts. measurements in September, October or November, and 0 otherwise, and month is the number of months since first observation. Note that the interaction term YR2013*Autumn is 1 only for the treatment group in the second period. Thus, the coefficient of interest is $\beta_{3}$, which measures the treatment effect. It estimates the difference between the observed percentage of speeding after the policy shift and the expected percentage of speeding if the policy shift had not happened.

We implement equation (1) separately for three outcome variables, percentage of vehicles travelling above the speed limit (overall speeding), $>10 \mathrm{~km} / \mathrm{h}$ above speed limit and $>20 \mathrm{~km} / \mathrm{h}$ above speed limit (extreme speeding). Our unit of analysis is the measurement for a particular round, district and type of road. During analysis, we further control for district and type of road. In all, we have 387 observations ( 6 districts $\times 3$ road types $\times 11$ rounds in Lipetskaya; and 7 districts $\times 3$ road types $\times 9$ rounds in Ivanovskaya). We performed analysis in Stata10 using the linear regression function.

\section{RESULTS}

Figure 1 illustrates that the percentage of vehicles speeding was declining steadily until September 2013, when new enforcement rules were implemented. Overall speeding had declined 20 percentage points in Lipetskaya and 22 percentage points in Ivanovskaya; speeding more than $10 \mathrm{~km} / \mathrm{h}$ above the limit had declined by 16 and 18 percentage points, and extreme speeding ( $>20 \mathrm{~km} / \mathrm{h}$ above the limit) had declined by 7 and 9 percentage points, respectively.

However, approximately half of these gains were lost immediately after September 2013. Overall speeding increased 9 and 13 percentage points in Lipetskaya and Ivanovskaya, respectively. Similarly speeding more than $10 \mathrm{~km} / \mathrm{h}$ above the limit increased by 5 and 6 percentage points, respectively. Extreme speeding did not change appreciably. The reversal in speeding trends observed at oblast level was also observable in most districts of the two oblasts (data available on request).

Figure 2 illustrates the DiD estimate of the effect of the policy for different levels of speeding. After controlling for seasonality, overall speeding increased significantly by 13

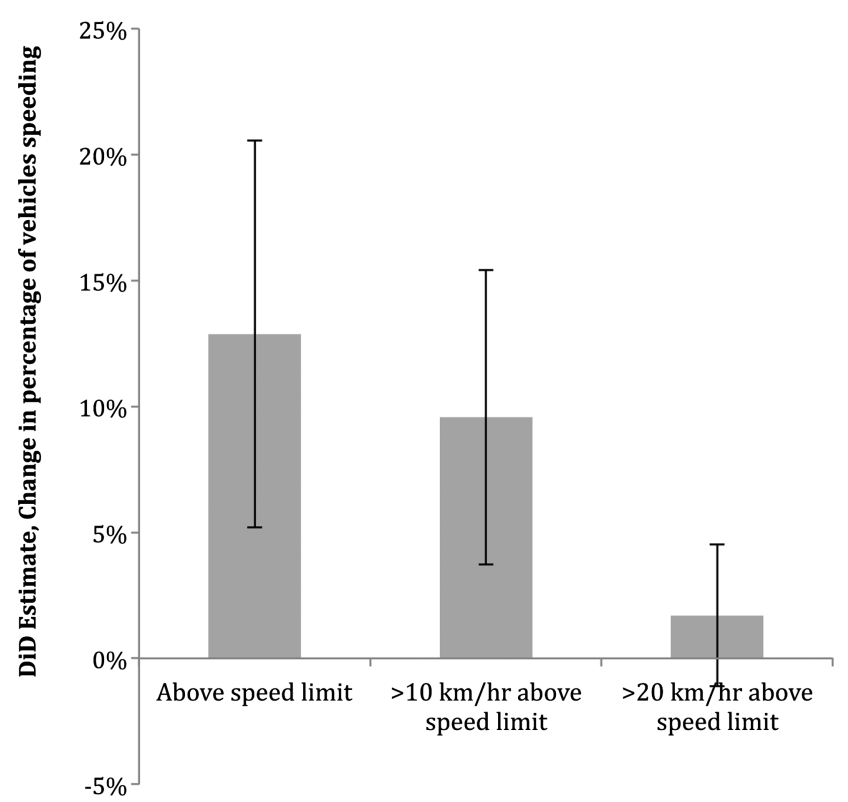

Figure 2 Change in percentage of vehicles speeding due to the elimination of fines. 
percentage points (95\% CI 4 to 19), speeding more than $10 \mathrm{~km} /$ h increased significantly by 10 percentage points (95\% CI 2 to 12) and extreme speeding increased but not significantly (1.7 pp, $95 \%$ CI -1.1 to 4.5 ).

\section{DISCUSSION}

Our data illustrate that strong progress was being made towards effective speed control in two regions of Russia since 2011. However, it appears that much of these gains were lost immediately following relaxation of the speed enforcement law in September 2013. We have been monitoring improvements in road safety in the two regions in response to ongoing road safety efforts that include interventions to reduce speeds. The steady declines in speeding that occurred prior to September 2013 are likely due to increased use of automated speed cameras (fixed and mobile), which allow substantially higher levels of enforcement than is possible with manual policing. The increasing enforcement has occurred alongside social marketing campaigns encouraging drivers to reduce speed.

Police statistics indicate that during the first 8 months of 2013 , the number of speeding tickets issued was $82 \%$ higher in Lipetskaya and $162 \%$ higher in Ivanovskaya compared with the same period in 2012 (WHO-Russia Office, personal communication, 2013), consistent with observed declines in speeding. However, elimination of fines for driving up to $20 \mathrm{~km} / \mathrm{h}$ above the speed limit appear to substantially reduce effectiveness of these systems, leading to large increases in the prevalence of speeding. Besides the negative impact of the new policy, these results also highlight the effectiveness of automated speed cameras at controlling speeds, in general.

In contrast with much of the media coverage and public debate, the new law has likely harmed road safety in Russia. Public attention has focused primarily on the increase in penalties for extreme levels of speeding ${ }^{6}{ }^{11}$ ignoring the removal of penalties for lower levels of speeding, which are much more common. However, our results show that not only were there large increases in overall speeding and in speeding more than $10 \mathrm{~km} / \mathrm{h}$ above the limit, there were no declines in extreme speeding. Thus, even the potential gains of increased fines for extreme speeding have not occurred.

The main limitations of this study are as follows. First, at this time only two rounds of speed measurement are available after the shift in policy. This limits the statistical analysis that can be performed on the data and is reflected in the uncertainty in our estimates (figure 2). Additional measurements over coming months will add strength to the findings. Second, no control sites (ie, sites where the new policy did not apply) were available because the change in enforcement is expected to have affected all our measurement sites simultaneously. Finally, sufficient amount of data on injuries and crashes is not yet available postpolicy to directly evaluate the impact on human health. While our analysis focuses on absolute speed, other studies show that speed dispersion is another important predictor of crash outcomes. ${ }^{12}{ }^{13}$ Further, most studies show that crash rates increase faster with an increase in speed on minor roads than major roads. Thus, the magnitude of the health impact due to the policy change is difficult to predict. Since road traffic injuries are highly seasonal, it will likely take many months before enough data are available to draw inferences.

However, existing evidence on the relationship between vehicle speed and the risk of a crash and the probability of death in the event of a crash ${ }^{12} 1415$ suggests that the new policy will likely result in a net increase in injuries. The new policy is equivalent to raising the speed limit by $10 \mathrm{~km} / \mathrm{h}$. In Israel, an increase of this magnitude resulted in a $15 \%$ increase in deaths and $38 \%$ increase in case fatality rates on interurban roads. ${ }^{16}$ We hope these early results will encourage Russia to reinstate these speeding fines and return to evidence-based approaches to road safety policy.

\section{What is already known on the subject}

- Reducing vehicle speed is among the most effective road safety strategies.

- Enforcement using automated speed cameras is an effective method of speed control.

\section{What this study adds}

- Russia's new policy eliminating fines for driving up to $20 \mathrm{~km} / \mathrm{h}$ above the speed limit resulted in a large increase in the prevalence of speeding.

- Road traffic injuries will likely increase in Russia unless speeding fines are reinstated.

Acknowledgements This work was conducted as part of the Global Road Safety Programme, funded by Bloomberg Philanthropies. KB had full access to all of the data in the study and takes responsibility for the integrity of the data and the accuracy of the data analysis.

Contributors All authors meet the uniform requirements for manuscripts submitted to medical journals and contributed to analysis and interpretation of findings, and the writing of the manuscript. All authors have seen and approved the final version of the paper.

Funding Bloomberg Philanthropies.

Competing interests None.

Provenance and peer review Not commissioned; externally peer reviewed.

\section{REFERENCES}

1 World Health Organization. Speed management: a road safety manual for decision makers and practitioners. Geneva: World Health Organization, 2008.

2 Wilson C, Willis C, Hendrikz JK, et al. Speed enforcement detection devices for preventing road traffic injuries. Cochrane Database of Systematic Reviews. 2006;(2): CD004607-CD004607.

3 Pilkington P. Effectiveness of speed cameras in preventing road traffic collisions and related casualties: systematic review. BMJ 2005;330:331-4.

4 Carnis LL, Blais EE. An assessment of the safety effects of the French speed camera program. Accid Anal Prev 2013;51:301-9.

5 Thorpe N, Fawcett L. Linking road casualty and clinical data to assess the effectiveness of mobile safety enforcement cameras: a before and after study. BMJ Open 2012;2:pii: e001304.

6 Buranov I. Big fines fail to deter speeding Russian motorists. Russia Beyond the Headlines, Rossiyskaya Gazeta. http://rbth.ru/society/2013/11/11/big_fines_fail_to_ deter_speeding_russian_motorists_31639.html. Published November 2013.

7 State Duma of the Russian Federation. Amendments to the code of administrative offences of the Russian Federation, Federal Law No 196-FZ. Moscow, Russia; 2013.

8 Hyder AA, Allen KA, Peters DH, et al. Large-scale road safety programmes in lowand middle-income countries: an opportunity to generate evidence. Global Public Health 2013:8:504-18.

9 Slyunkina ES, Kliavin VE, Gritsenko EA, et al. Activities of the Bloomberg Philanthropies Global Road Safety Programme (formerly RS10) in Russia: promising results from a sub-national project. Injury 2013;44(Suppl 4):S64-9.

10 Ashenfelter 0, Card DE. Using the longitudinal structure of earnings to estimate the effect of training programs. National Bureau of Economic Research, 1984.

11 Obrazkova M. Officials look to end aggressive driving in Russia. Russia Beyond the Headlines, Rossiyskaya Gazeta. http://rbth.ru/society/2013/09/04/officials_look_to_ end_aggressive_driving_in_russia_29477.html. Published September 2013. 
12 Aarts L, van Schagen I. Driving speed and the risk of road crashes: a review. Accid Anal Prev 2006;38:215-24.

13 Taylor MC, Lynam DA, Baruya A. The effects of drivers' speed on the frequency of road accidents. UK: Tranport Research Laboratory, 2000.

14 World Health Organization. World report on road traffic injury prevention. Geneva: World Health Organization, 2004.
15 Richards DC. Relationship between speed and risk of fatal injury: pedestrians and car occupants. Transport Research laboratory, Department for Transport: London; 2010:1-41. http://www.dft.gov.uk/pgr/roadsafety/research/rsrr

16 Richter ED, Barach P, Friedman L, et al. Raised speed limits, speed spillover, case-fatality rates, and road deaths in Israel: a 5-year follow-up. Am J Public Health 2004;94:568-74.

\section{US data lacking to track child shootings}

Although data are plentiful to describe gun victims, too little information exists to identify characteristics of child shooters. J Vernick, co-director of the Hopkins Center for Gun Policy and Research, asserts that these data are needed to improve prevention. Predictably, the NRA is opposed to this appeal, asking why Centers for Disease Control is 'doing this type of thing, when it's their job to be dealing with disease and this isn't a disease.'

Editor's Comment: Teret and Baker addressed this topic in Inj Prev 1995;1:3 139.

\section{Massachusetts has lowest US gun death rate}

Fewer people die from gun violence in Massachusetts than anywhere else in the USA. States with the most lenient gun laws had higher gun ownership and the highest gun death rates. Other states with low rates are Rhode Island, New Jersey, New York and Hawaii. The rate for the USA is 10 times that of the UK and Australia.

\section{Samsung S-drive programme}

An initiative by Samsung called the S-drive seems encouraging in combating drive texting. The app, designed for Samsung phones, forces drivers to only make and respond to auditory commands.

\section{Car decals linked to fewer crashes}

A study in the Am J of Preventive Medicine found that including a decal as part of New Jersey's Graduated Driver Licensing programme is 'associated with a sustained two-year decline in crash rates among intermediate (i.e., probationary) teen drivers.' The decal is a reflective patch on the license plates of cars driven by those aged 16 to 20 years. Remarkably, $\mathrm{NJ}$ is the only state requiring some means of notifying others that the driver is a novice.

Editor's Comment: In the UK, an L plate has been used for decades. 